\title{
Unprecedented regio and stereocontrol in Povarov reaction of benzylidene-(3-nitrophenyl)amine
}

\author{
Paul J. Stevenson* and Isla Graham \\ School of Chemistry, Queen's University, Belfast BT9 5AG Northern Ireland \\ E-mail:p.stevenson@qub.ac.uk
}

\section{Dedicated to Professor M. A. McKervey on the occasion of his 65th birthday}

(received 01 Mar 03; accepted 25 Apr 03; published on the web 08 May 03)

\begin{abstract}
Typically, Povarov reactions of imines derived from aromatic amines and aromatic aldehydes show poor exo/endo-stereoselectivity and to date no data is available on the regioselectivity of the cyclisation when 3-substituted imines are employed. We have demonstrated that reaction using acyclic enamides as the alkene component with 3-nitro substituted imines is completely regioselective and gave only the 5-nitro substituted tetrahydroquinoline. As a bonus the reaction also became completely exo-selective with the stereochemistry of the E-alkene preserved in the tetrahydroquinoline product.
\end{abstract}

Keywords: Povarov reaction, regioselective, imines, yttrium triflate, tetrahydroquinolines

\section{Introduction}

In the 1960's Povarov discovered that imines 1 derived from aromatic amines undergo Lewis acid catalysed formal [4+2]-cycloaddition with electron rich alkenes to give tetrahydroquinolines 3, Scheme 1. ${ }^{1}$ Typically the alkenes employed were electron rich, with enol ethers being the most widely studied substrates to date. The mechanism for this process is undoubtedly stepwise proceeding via ionic intermediate 2 with the final step being an intramolecular electrophilic substitution of a carbenium ion. Loss of alkene stereochemistry in the product and poor exo/endo selectivity are synonymous with this reaction. There has been a resurgence of interest in this chemistry when Kobayashi demonstrated that lanthanide triflates were efficient catalysts for effecting this transformation ${ }^{2}$ and more recently that benzotriazoles reacted with electron rich alkenes to give the same products as those of the Povarov reaction. ${ }^{3}$ Depending on the reaction conditions tetrahydroquinolines 3 or quinolines $\mathbf{4}$, formed by Lewis acid promoted loss of ethanol followed by aerial oxidation, were the main products of Povarov reaction. ${ }^{4}$ 


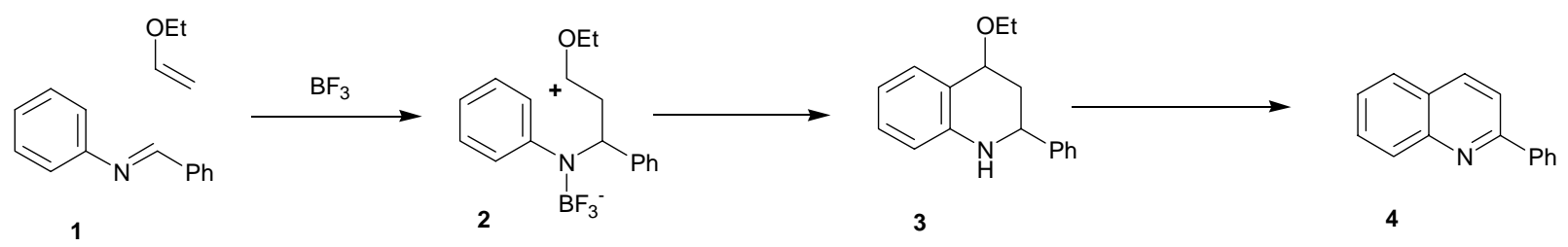

Scheme 1. Povarov reaction giving tetrahydroquinoline and quinoline products.

Despite the enormous potential of this reaction it has rarely been used in synthesis. Recently we $^{5}$ and others ${ }^{6}$ demonstrated that Povarov chemistry can be extended to using cyclic enamides as the alkene component, and this has led to two syntheses and a formal synthesis of martinellic acid. We have also demonstrated facile cyclisation elimination reactions ${ }^{7}$ leading to heterocycle 5 a key intermediate in the synthesis luotonin . $^{8}$

5-Methoxy substituted quinolines are a common structural feature in a number of biologically active quinoline alkaloids, for example 9-methoxycamptothecin $\mathbf{6 b},{ }^{9} \quad 9-$ methoxymappicine ketone $\mathbf{7 b} \mathbf{b}^{9}$ and $S$-9-methoxymappicine $\mathbf{8 b} .{ }^{9}$ This latter alkaloid is also known as nothapodytine A. ${ }^{10}$ Although there has been much synthetic interest in the non-substituted alkaloids $\mathbf{6 a - 8 a},{ }^{11}$ to date there has been very little synthetic endeavor in the 9-substituted versions. We envisaged that rapid access to this substituted heterocyclic system could be obtained by a Povarov cyclisation elimination strategy. However, to be successful it was necessary that the initial Povarov cycloaddition showed regioselectivity, for a 3-substituted imine, at the sterically congested 2-position over the 6-position.

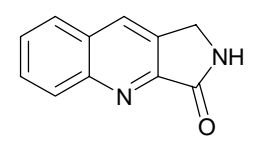

5

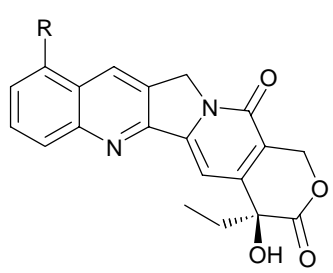

$6 \mathrm{a} \mathrm{R}=\mathrm{H}$ 6b $R=O M e$

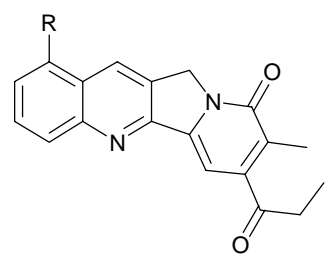

$7 \mathrm{a} \mathbf{R}=\mathrm{H}$ 7b $\mathrm{R}=\mathrm{OMe}$

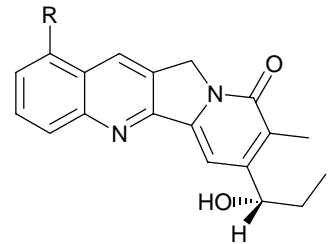

$8 a \mathrm{R}=\mathrm{H}$ $8 b \mathrm{R}=\mathrm{OMe}$

Scheme 2. Luotonin A precursor and a range of bioactive quinoline alkaloids isolated from nothapodytes foetida with and without substituents at C9. 


\section{Results and Discussion}

3-Substituted imines $\mathbf{9 b}$-d were readily prepared by condensation of the corresponding aromatic amines with benzaldehyde. ${ }^{12}$ Attempted Povarov reaction of these substrates with ethyl vinyl ether using catalytic quantities ( 2 mol \%) of yttrium triflate proved extremely precocious and only intractable material was produced in all cases. We next turned our attention to enamide $\mathbf{1 0}$ as a potential coupling partner. Enamide $\mathbf{1 0}$ was readily available in large quantities by condensation of pyrrolidinone with heptanal catalysed by p-toluenesulphonic acid with azeotropic removal of water. Compound $\mathbf{1 0}$ was formed exclusively as the $E$-alkene and the stereochemistry was readily assigned by measurement of coupling constant, $\mathrm{J}=17.7 \mathrm{~Hz}$, of the alkene protons. In a previous study, we demonstrated that enamide $\mathbf{1 0}$ underwent clean Povarov reaction with unsubstituted imine 9a to give a 2:1 mixture of tetrahydroquinoline diastereoisomers 11a and 12a. ${ }^{13}$ The formation of substantial amounts of isomer 12a is very significant as the stereochemistry of the alkene is not preserved in the tetrahydroquinoline. This provides strong evidence that this diastereoisomer was not formed by a concerted pathway and it was also likely that compound 12a was formed by a stepwise process with thermodynamics dictating the trans-relative stereochemistry between C3 and C4. The stereochemistry of isomers 11a and 12a was readily assigned by measurement of the vicinal coupling constants for protons $\mathrm{H} 2$ and $\mathrm{H} 4$ in the tetrahydroquinoline portion of the molecule.

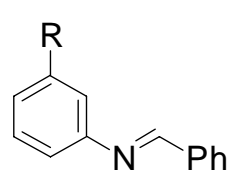

$9 \mathrm{a} \mathrm{R}=\mathrm{H}$ $9 \mathrm{~b} R=\mathrm{OMe}$ 9c $\mathrm{R}=\mathrm{NO}_{2}$ 9d $\mathrm{R}=\mathrm{CH}_{3}$

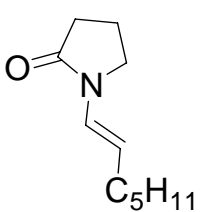

10

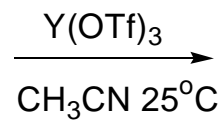

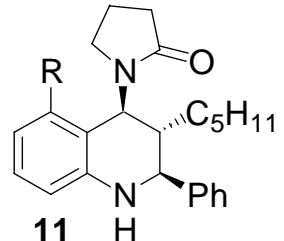

$11 \mathrm{H}$

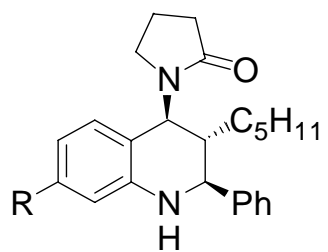

13
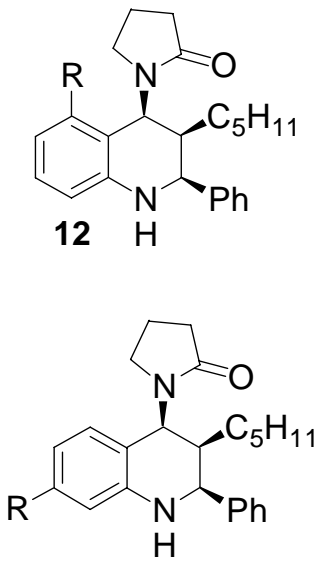

14

Scheme 3. Reaction of 3-substituted imines with an acyclic enamide.

The most direct route to 5-methoxytetrahydroquinolines $\mathbf{1 1 b}$ and $\mathbf{1 2 b}$ would be direct reaction of imine 9b with enamide 10. However, despite extensive experimentation, no identifiable products could be isolated from this reaction. In all cases, the imine and most of the enamide were consumed but only intractable material was produced. We next turned to the imine 9c derived from 3-nitroaniline. We have previously shown that Povarov reactions readily proceeded with imines derived from amines containing strongly electron withdrawing groups at the 4-position, ${ }^{13}$ so reactivity was not percieved to be a problem with this substrate. In principle, 
nitro groups can be converted to methoxy groups via the diazonium salt. Incredibly imine 9c reacted smoothly with enamide $\mathbf{1 0}$ and gave exclusively adduct $\mathbf{1 1}$ both as a single regioisomer and as a single diastereoisomer (stereochemistry as shown) which crystallised from the reaction mixture making isolation an easy task. The regioselectivity of the cycloaddition was readily determined from proton nmr data. In the aromatic region of the spectrum protons H6, H7 and H8 were readily identified by their chemical shifts. Their multiplicities, (doublet, triplet, doublet respectively) confirmed the regiochemistry of the cycloaddition was as shown. The stereochemistry of the three contiguous chiral centres on the tetrahydroquinoline fragment was readily assigned by measurement of vicinal coupling constants $\mathrm{J}_{\mathrm{H} 2 \mathrm{H} 3}=8.9 \mathrm{~Hz}, \mathrm{~J}_{\mathrm{H} 3 \mathrm{H} 4}=8.6 \mathrm{~Hz}$ which suggested the stereochemistry depicted. These $\mathrm{J}$ values are a little lower than the corresponding unsubstituted isomer 11a, suggesting that the 5-nitro group has an influence on the conformation of the saturated ring. It is tempting to suggest that the cycloaddition may be a concerted process when a conjugating strongly electron withdrawing nitro group is attached to the aromatic ring. However, it is more likely that when regioisomer $\mathbf{1 1}$ is formed, there is more steric hindrance from the proximal nitro group and this makes the 3,4-trans-isomer 11c thermodynamically much more stable than the 3,4-cis-isomer 12c.

Because isomer 11c crystallised from the reaction mixture there was the distinct possibility that the other isomers 12c-14c were forming, but removal of isomer 11c was driving the equilibrium to ultimately give one compound. We have previously shown that Povarov reactions with cyclic enamides are reversible albeit with a slow reverse reaction. ${ }^{7}$ To check that this was not happening, a reaction was run in d3-deuterioacetonitrile and monitored by proton nmr spectroscopy. This experiment clearly showed that only one isomer was produced, 11c proving that insolubility of the product was not dictating the outcome of this reaction.

The question then arises as to why the reaction should show such remarkably high regioselectivity. For aromatic compounds containing conjugating electron withdrawing groups, the electron density is by far the greatest at the 3-position, but it is noteworthy that the electron density at the 2-position is much greater than that at the 4 -position. ${ }^{14}$ Therefore, in electrophilic substitution reactions with hard electrophiles, substitution is dominant at the 3-position but the ratio of minor 2- and 4-substituted isomers can be greater than 10:1. Therefore, when the 3position is blocked, as in our case, there is an electronic preference for reaction to proceed at the 2-position, which is observed. What is currently unclear is why the regioselectivity should be so high for such a congested position.

When imine 9d containing an electron donating methyl group was employed, an inseparable 1:1:1 mixture of three isomers resulted. Because these isomers could not be separated, the regio and stereochemistry of the cycloaddition could not be determined. However, it can be confidently stated that the regioselectivity was very poor in this case.

In conclusion we have demonstrated the first regioselective Povarov reaction of a 3 -nitro substituted imine. Although a strong electron withdrawing group was required to obtain the desired selectivity, the reaction should be synthetically useful as the nitro group is readily converted to a wide range of other functionalities via the diazonium salt. 


\section{Experimental Section}

General Procedures. Melting points were recorded using a Kofler hot stage apparatus and are uncorrected. I.R spectra were recorded on a Perkin-Elmer Model 983G instrument coupled to a Perkin-Elmer 3700 Data Station as potassium bromide $(\mathrm{KBr})$ disks, or films (liquids). NMR spectra were recorded at $500 \mathrm{MHz}$ and $75.4 \mathrm{MHz}$ using Bruker DRX500 and DPX300 nmr spectrometers respectively. Mass spectra were recorded using Double Focusing Triple Sector VG Auto Spec and microanalysis was obtained using a Perkin Elmer 2400 CHN elemental analyser.

The imines $\mathbf{9 b}$-d and the acyclic enamide $\mathbf{1 0}$ were made by the literature procedures. ${ }^{12,13}$

\section{1-(3-Pentyl-2-phenyl-5-nitro-1,2,3,4-tetrahydroquinolin-4-yl)pyrrolidin-2-one (11c).}

Yttrium triflate (44mg, $0.08 \mathrm{mmol})$ was added to a solution of 1-[(1E)-hept-1-enyl]pyrrolidin-2one $10(0.72 \mathrm{~g}, 4.0 \mathrm{mmol})$ and benzylidene-3-nitroaniline 9c $(0.95 \mathrm{~g}, 4.0 \mathrm{mmol})$ in acetonitrile (10ml). After stirring for one week at room temperature compound 11c crystallised from the reaction mixture $(1.2 \mathrm{~g}, 75 \%)$ as yellow prisms $\mathrm{mp} 238-239^{\circ} \mathrm{C}$. The sample was both analytically and isomerically pure. $\mathrm{C}_{24} \mathrm{H}_{29} \mathrm{~N}_{3} \mathrm{O}_{3}$ requires $\mathrm{C} 70.7, \mathrm{H}$ 7.1, $\mathrm{N}$ 10.3. Found: $\mathrm{C}$ 70.4, H 6.8, N 10.2; m/z (\%) (M+1) 408 (26), $\mathrm{M}^{+} 407$ (94), 390 (100), 361 (49), 322 (26), 316 (29), 266 (39), 251 (56), 245 (34), 206 (23), 205 (29), 91 (27); $v_{\max }\left(\mathrm{KBrcm}^{-1}\right):$ 1161, 1283, 1335, 1612, 2854, 2924, 3309; $\delta_{\mathrm{H}}\left(300 \mathrm{MHz}, \mathrm{CDCl}_{3}\right) 0.76\left(3 \mathrm{H}, \mathrm{t}, \mathrm{J}=7.1 \mathrm{~Hz},\left(\mathrm{CH}_{2}\right)_{4} \mathrm{CH}_{3}\right), 1.13\left(8 \mathrm{H}, \mathrm{m},\left(\mathrm{CH}_{2}\right)_{4} \mathrm{CH}_{3}\right), 1.60$ $\left(2 \mathrm{H}, \quad \mathrm{m}, \mathrm{CH}_{2} \mathrm{CH}_{2} \mathrm{CO}\right), 2.29\left(1 \mathrm{x} 2 \mathrm{H}, 1 \mathrm{x} 1 \mathrm{H}, 2 \mathrm{xm}, \mathrm{CH}_{2} \mathrm{CH}_{2} \mathrm{CO}, \mathbf{H}-3\right), 2.91$ (2x1H, 2xm, $\left.\mathrm{NCH}_{2} \mathrm{CH}_{2}\right), 4.29$ (1H, d, J=8.6Hz, H-2), 4.40 (1H, s, NH), $5.52(1 \mathrm{H}, \mathrm{d}, \mathrm{J}=8.9 \mathrm{~Hz}, \mathbf{H}-4), 6.73$ (1H, d, J=7.1Hz, H-8), 6.95 (1H, d, J=6.7Hz, H-6), 7.15 (1H, t, J=7.9Hz, H-7), 7.41 (5H, m, ArH); $\delta_{C}$ $\left(75.4 \mathrm{MHz}, \mathrm{CDCl}_{3}\right)$ 13.94, 17.99, 22.30, 25.31, 28.96, 30.56, 31.92, 41.08, 43.67, 49.94, 58.29, 111.59, 112.89, 117.62, 127.24(2C),128.18, 126.67, 128.70(2C), 140.93, 147.17, 151.38, 175.16.

\section{References}

1. Povarov, L. S. Russian Chem. Rev. 1967, 36, 656.

2. Kobayashi, S.; Ishitani, H.; Nagayama, S. Synthesis 19951195.

3. Katritzky, A.R.; Rachwal, B.; Rachwal, S. J. Org. Chem. 1995, 60, 3993.

4. Makioka, Y.; Shindo, T.; Taniguchi, Y.; Takaki, K.; Fujiwara, Y. Synthesis 1995, 7801.

5. (a) Hadden, M.; Stevenson, P. J. Tetrahedron Lett. 1999, 40, 1215. (b) Hadden, M.; Nieuwenhuyzen, M.; Osborne, D.; Stevenson, P.J. Thompson, N. Tetrahedron Lett. 2001 42, 6417.

6. (a) Powell, D.A.; Batey, R.A. Organic Lett. 2002, 4, 2913. (b) Batey, R. A.; Powell, D. A. J. Chem. Soc., Chem. Comm. 2001 2362. (c) Batey, R. A.; Simoncic, P. D.; Lin, D.; Smyj, R. 
P.; Lough, A. J. J. Chem. Soc., Chem. Comm. 1999 651. (d) Xia, C. F.; Heng, L. S.; Ma, D.W.; Tetrahedron Lett. 2002, 43, 9405.

7. Nieuwenhuyzen, M.; Osborne, D.; Stevenson, P. J. J. Chem. Soc., Chem. Comm. 2002, 444.

8. Osborne, D.; Stevenson, P. J. Tetrahedron Lett. 2002, 43, 5469.

9. Das, B.; Hadhusudhan, P.; Tetrahedron 1999, 55, 7875.

10. (a) Wu, T.S. Chan, Y. Y. Leu, Y. L. Chern, C.Y. Chen, C.F. Phytochem. 1996, 42, 907. (b) Bodger, D. L.; Hong, J. J. Am. Chem. Soc. 1998, 120, 1218.

11. (a) Comins, D. L.; Nolan, J. M. Org. Lett. 2001, 3, 4255. (b) Yabu, K.; Masumoto, S.; Yamasaki, S.; Hamashima, Y.; Kanai, M.; Du, W.; Curran, D. P.; Shibasaki, M. J. Am. Chem. Soc. 2001, 123, 9908. (c) Ishibashi, H.; Kato, I.; Takeda, Y.; Tamura, O. Tetrahedron Lett. 2001, 42, 931. (d) Toyota, M.; Komori, C.; Ihara, M. J. Org. Chem. 2000, 65, 7110. Mekouar, K.; Genisson, Y.; Leue, S.; Greene, A. E. J. Org. Chem. 2000, 65, 5212.

12. (a) Smith, S. J.; Zimmer, H.; Fluck, E.; Fischer, P.; Phosphorus and Sulphur 1988, 35, 105.

(b) Bernasconi, C. F.; Renfrow, R. A. J. Org. Chem. 1994, 59, 5404. (c) Ward, C. J.; Patel, O.; James, T. J. Chem. Soc., Perkin Trans. 1 2002, 462.

13. Hadden, M.; Nieuwenhuyzen, M.; Potts, D.; Stevenson, P. J.; Thompson N. Tetrahedron 2001, 57, 5615.

14. Fleming, I. Frontier Orbitals and Organic Chemical Reactions, Wiley: London 1976; p 62. 